\title{
How to accommodate grief in your life
}

Louisa Minkin, University of the Arts

Francis Summers, UCA, Rochester

\begin{abstract}
\end{abstract}
This artists' text examines the relationship between photographic images and Massively Multiplayer Online (MMO) environments. We note that such scripted image worlds necessitate a fundamental reconsideration of the capacities of image, its formation, reproduction, storage and circulation. As an archaeologist would document an excavation, extending conventional methods through 3D visualization technology to work in new ways with the archaeological record, we chose to document a world built and razed digitally by a now dormant group of anonymous gamers called the Yung Cum Bois (YCBs). We turn to some definitions of griefer as a subcultural phenomenon within online culture to attempt to contextualize our involvement some more, thinking through the forms of image-gathering that grief play has generated, such as scripted object attacks where image-objects spawn and self-replicate, continually spurting out copies of themselves, lagging the region, slowing down frame rates, consuming land resources. Here we witness images blockading network logistics. This was active fieldwork. We got involved. We applied visualization technology learnt from archaeological computing research to the avatars, temporary structures and abandoned ruins of an online world, Second Life $(S L)$. We patched together a kind of virtual photogrammetry, enabling the monumentalization of avatars, objects and scenarios, recompiling these into new configurations and uploading them freely to be reused, detourned and weaponized by our virtual friends. 
We situate this endeavour within a cobbled history of imaging technology, the networked self and its pathologies, riffling through our own image dump. Here.

\section{Keywords}

photogrammetry

photography

online relations

griefing

computer game culture

3D imaging

spam

photomontage

Second Life 
Wait.

Wait.

Wait.

Pliny the Elder gives us a story of shadows and shapes.

The nameless daughter of Butades the potter traces out by lamplight the silhouette of her lover's shadow on the wall. He heads for the battlefield; the inference is that he will not return. She waits for an absence that she has marked out. Prolonging and longing are organized around a shadow. The silhouette, in this case, demarks a stereotypical, sentimental gender position. The thin outline of absence, a souvenir of socio-military sacrifice, becomes the manifestation of a token: a medal valorizing the production of widows. Index is made to be coterminous with affect. Commonly announced as an origin of painting, in fact we are told that Butades filled in the outline by compressing clay upon the surface and so made a face in relief, which he hardened by fire: an extrusion of shadow, an extension of image, extemporized.

If Butades' daughter was engaged in data capture as she marked out the silhouette, we see immediately that data collection is not a neutral activity. It is a material interaction producing new entities, affects and artefacts. Victor Stoichita takes Pliny's story as a first position in a history of the shadow, marking out a counter-history to foundation myths of representation, a floundering, akin to grieving. This is the story of an indexical tracing that shows us a life to grieve, a process of representation given over to the task of mourning. The stories we have of 
photography are infested with ghosts and the dead that refuse to die, with remembrances that are continually over-registered by the photographic trace.

In 1863 François Willème patented an apparatus for turning photographs into sculpture. This largely forgotten device was one of the many curious machinic assemblages beached by the positivist wave of technological innovation we see as characteristic of the nineteenth century. Willème's project does not use the serial, cinematic model familiar from Muybridge, but instead spatializes multiple, synchronous images. Shots angled at $360^{\circ}$ around a central subject are aggregated as system. Outlined sequentially into clay, cut turn by turn, a set of silhouettes produces a statuette: the sum of the profiles. Willème's work provides an antecedent for photogrammetry and 3D prototyping, arguably even prefiguring parallel processing and providing an ancestor for the information model.

Photogrammetry gathers image into gestell. Grammatization is a privileging of calculation: we delegate our synthetic capacities to the algorithm. Our material histories shift. One characteristic of 3D modelling applications is the production of a hollow body, something akin to Walter Benjamin's description of the discarded fetish - second nature - a reified, dead world. Data take on a new presence as skin: a digital flaying or appropriation.

Data capture is a form of spoliation, a stripped asset.

Decimation and interpolation succeed literary modes of interpretation and translation. Computational methods are without qualitative agency, methods of numerical management, piloted feedback loops.

bots don't cry.

i know you're fucking yourself on an alt 


\section{let me in}

We turn to our current stories of photography. A flash flood of photographs incorporated into cybernetic systems, insubstantial shadows and embodied desires, real bodies and virtual presence, narcissus and technocracy: a networked emotional life spelled out largely through the grammar of pictures, supplemented by a dwindling number of characters or as looped six-second vines. The ghosts that are haunting us here are not indicating towards a future death but point their index finger at an anxiety of a death in the now - a dearth of relevance, of hits, of likes, of social visibility, a lack of reticular legibility and thus of techno-social obsolescence. Photography here can be understood as a technological practice for modulated behavioural selfsurveillance, a technology of the self that is perpetually mobile and subject to increased flexibility. The networked image requires critical questions of format, algorithm, data management and search engines, epistemologies of search, the production of subjectivity in the apparatus of the social networks and ideologies of sharing and generating content. A pathological ideology of individuation and participation. This image, spread across vectors, buoyed by diverse affective jolts and crashes, is to be understood within a particular set of cultural frameworks as well as within technical paradigms.

A programme running in the background, a Daemon, performs actions without conscious user interaction, monitoring, or logging notifications, and with them repressed memories, primal urges and unconscious habits are traced out. It is always active, always there. We ourselves are overclocked, tooled into a system that works faster than our synapses. The network overheats, our nervous systems overload. We are burnt out, subject to visual trauma. Green flashing triangles appear on the screen; 
dancing pixels indicate failures of memory. Push it harder and black circles knock us offline. Apotropaic blobs indicate the entire OS crashing. At this point reason collapses into redundancy.

Physiological autonomics produce sociocultural automatism - habits, gestures, speech acts. We feel the incorporation of knowledge into the body, the restructuring of nerves and brain. Technological automatisms - predictive text, browser history: these are the technical traces databased to generate our intentions, predict our futures. Narrative as a function of probability.

In this scenario there is an unparalleled opportunity to meet and talk with everyone on the globe instantaneously. Amidst this utopia, a democracy of users adding their voice to an affirmative chorus of self-love and friending, there are numerous shadows lurking. For every 'share' we might say there is an 'un-share' (even if there is no button for that function); for every communication there is a spam (the majority of e-mail content on the web); for every comment board there is a troll (the deceptive manipulator of language and identity); for every kind word there is a flaming comment (the demonstration that communication is never 'friction-free'); for every interactive possibility there is a griefer (waiting to drink your delicious tears).

We are extolled to increase / accumulate our social capital into digitized and monetized structure: the structure of friending as the accumulation of a certain 'friendship capital' - merely one offshoot of 'human capital', a utilization of the general intellect as framework for a new economy of relations.

woodbury died

the goons died

digital worlds died 
and everyone collected together

at a sim

called rancour

hashtag rly messed up

Politics, says Vilem Flusser, is the distinction between a private space and a

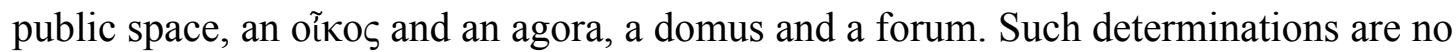
longer clear. How then shall we meet? The agoraphobic limps, traverses the borders, stops to tie her shoes too often. Military pilots suffer simulator sickness. Real and virtual spaces have their pathologies and produce symptoms, sicknesses and humiliations. Solitary confinement may loosen a prisoner's sense of the coherence of objects in space. Orientations in virtual space are similarly disturbed; a consistent model viewed from one angle may explode into incoherence from another. How then do we hold together? Virtual communities operate as laboratories for conducting experiments in the construction of new societies and governance structures. Business as usual. Collectivities are put to work: we meet in the sandbox, the commons where we build together, share scripts, form a group. Sooner or later someone gets thirsty; foreclosures occur. We can no longer gloss over the wound of antagonism.

We get kicked from chat. Scapegoated, our exile a remedy for the group. Alongside shunning, blocking, muting, de-rendering - the ex-communcations at hand - there are virtual expropriations; the banhammer falls; our home can no longer be found. Creative work here is at the mercy of the platforms hosting us; at stake in risking a ban is loss of inventory, loss of content, loss of 'home'. Possession of a digital asset we note is actually a permission to access. Revokable without recourse. 
We exiled them for being a piece of shit

Kill meee now

youtube automated subtitle error: dead world = global

A history lesson of the present. Post-Fordism arrives as that which operates as a model of lean production that listens closely to the whims of the market it discerns through informational-linguistic technology. Records of sales and the monitoring of opinion, rather than policy or planning, is what commands production. Commodities keep in touch with the factory through a vast array of reticular feedback devices that inform the production process as to just what needs to be made. Rigidity, specialization, and overproduction are the mortal sins of this developed just-in-time economy. Mobility, connectivity, adaptability and flexible responsiveness are the new forms of grace. This leads to the emergence of a contemporary catechism: To keep in touch is divine. The establishment of connections is a particular form of enabling production, be that inter-subjective - our warm human relations - or between consumer patterns and factory. A language of self-management. A communicative governance.

The communicative sphere, far from being a public realm, becomes a specifically productive realm. Techno-linguistic managerial organization is a world apart from that which keeps open the door to social freedom. Linguistic connectivity is accompanied by a self-regulating irrational exuberance; happiness and fulfilment are the expected emotional 'tone' - an horizon that guides our actions. The cultural super-egoic injunction is not merely to be 'good' but to be a 'friend' who is totally 
stoked to link you with a hashtag. In the words of John Kelsey we are afflicted by a dis-ease of metropolitan togetherness.

In this world of intensified semio-info-sensual overload, as Bifo Beradi notes, the human organism has a tendency to turn to simplification to survive: with smoothed psychological responses and constantly repackaged affect. Faster feeling without complication. Contractions of affect define the emotional life of the network. Without the time for an adequate 'elaboration of emotions' this life is one that attempts a friction-free experience of perpetual positivity and euphoria but is plagued by panic, depression and anxiety.

Engulfed, engulfing and enflamed.

We might say that our capacity to communicate and to interrelate becomes subject not only to measurement but also to formatting - a managed mode of encounter (where the battle is over the correct and legitimate tone of communication).

This situation is one of a libidinal economy - where there is a play on our cathexes to objects and each other, whilst the perpetually lacking aspect of desire is enforced. Here there is a grammatization of gesture and memory - a making discrete of knowledge and action from the body to the reproductive social machine; the abstraction of the subject to the user, a sinking of agency into the glacial flatness of the profile. The driving force of this communicative economy is both a harnessed libidinal force (the simple desire for contact, belonging and encounter) and the alienation of cognitive labour and affect, an exteriorization of feelings and memory, of know-how and solidarity, diffused into the virtual space of connective castration. Or, using the terms of Bernard Stiegler, in the current stage of control societies where subjects are not enclosed in the factory but 'modulated' in the network, there is distinct work on our 'neurochemical activity' as well as on our 'neurobiological 
substrates of memory and knowledge' - a scenario not only of society, industry and biopolitics but also of the 'psychopolitical' and the 'industrial economy of memory'.

The reticular network as site of uppers and downers, then.

A labour where forgetting is not part of a grieving process, but part of our feelgood mnemo-affective-proletarization.

We find ourselves in a post-community where emotional life is a formatted component, with connection and connectivity defined as a 'functional relationship' a clear model of productivity. The network here can be seen as extimate (Lacan's conflation of complete intimacy and absolute exteriorization). It is against this that Kelsey asks us to consider what worth there might be in returning to Baudelaire's aesthetics of disgust, the re-affirmation of spleen as that resistant affect that remains while all others are put to productive labour. Spleen, he notes, is an affect that refuses employment and formats. It is a way of thinking of a distinct 'otherness' within communication, a splenetic move beyond the abstraction of 'profile', a mode that both radically disconnects and works to erode hierarchies. This most Baudelairean affect is one that already shadows our networked existence; it is one explicitly connected to narratives of online behaviour deemed as emotional pathology and deviant conduct.

Figure 1: Stills from LM/FS (2016a), would you die for me, digital video, sound, 7:07.

he started putting python eggs everywhere like it was php 
One figuration of online spleen is the griefer, a phenomenon within the massive multiplayer online role playing game - from World of Warcraft to Minecraft to Call of Duty. The griefer as a term is one that arises in most discussions as a figure in the context of play, that supposedly purposeless activity, that supposed suspension of work. The video game is a distinct cultural form, a mass medium, a post-cinematic technology of immersion. Gaming is a famously uncivil culture, defined by action: to play rather than to read. Game spaces are a new agora: public, political, spaces of affect, belonging and foreclosure.

The griefer is one who engages in play and yet refutes the codes of conduct that most online players operate within, a figure of ruination who refuses the particular conduct of networked emotional life, of reticular goals and targeted activity.

The griefer is often described as one who adopts a style of play, grief play.

Some characteristics:

A refusal of friendship; a classic form of grief play is to kill your team, or prevent them from achieving their in-game goals. A post-convivial act.

Impersonation, deception, a violation of identity and personal(ity) verification.

Purposeful incompetence and the willed failure of a capacity to fulfil sharedimposed objectives; derailments of targeted, programmable action.

Destroying, spawning, crashing and blocking: a purposeful destruction of the objects of others, or the construction of objects that destroy goal achievement; the constructed failure of duty.

To cause distress intentionally; to explicitly refuse happiness (especially that of others).

To interfere with the suspended fantasmatic moment of a role play (to fuck with my moment). 
To spam, flame, troll, burn, hack.

To find exploits in both the software and the social relation.

To scam, copy, copybot, reduplicate, non-affiliate, loosen propriety ties...

To violate moral codes.

To build that which is not... correct.

To remind us all that internet $=$ serious business.

Not to ruin the game but to ruin your game.

Ad hominen as a lifestyle.

Griefing is the formula of immeasure. Hilarious dyspeptic dismeasure. A keen disposition towards schadenfreude, otherwise known as lulz. If we are pacified into the systematic delegation of our analytical functions to an involuntary, algorithmic pathway, then the hubristic griefer exploits the intervals, opens the possibility of catastrophe, winds you up, lets you down, confounds you. Hubris, says Stiegler, is the origin of every kind of singularity. Hubris, in Greek hybris, is the intentional use of violence to humiliate or degrade. The connotation changed over time, and hubris came to be defined as overweening presumption that leads a person to disregard the divinely fixed limits on human action in an ordered cosmos. Grief-play, we say, is a form of hubris in an algorithmic cosmos.

With the griefer we hear of malign behaviour, of the hurting, disheveling and humiliation of the average gamer through the bending/breaking/exploitation of loops or holes in game world software, keeping open wounds in the social texture of a community, to exploit the social code. Inflicting trauma on others. We hear of meat grinder tactics, chokepoints and killstreaks. Stream-sniping. Metagaming.

An historical context is provided by Gabriella Coleman who situates the griefer within the online practice known as trolling - the art of deception and communicative 
misdirection. Against the practice of having a verifiable identity and a clear intention, trolling can be understood within Coleman's terms as an online practice that performs a linguistic spectacle rather than a productive encounter: replacing consensual, bordered, reasoned debate with actions outside of the range of common conduct.

As a shadow of an older Internet this figure is one who reminds us of a time when identity online was never a given and where alternate modes of human, machinic, and libidinal relations might be played out, where fantasies of an alternative life prevailed. Freedom from meatspace coordinates. Listen to an old call, listen to VNS Matrix, they wanted to shut down the Big Daddy mainframe, to terminate patriarchal relations. To be positive anti-reason, to terminate moral codes, to become the future cunt.

Now, to comprehend the devastating silence of current Internet anomie, the deafness to such a call; lets google 'beach ready'.

Done it? So far, so good. Freedom and governance incorporated, incarnated, vaporized into a digital stimmung, the algorithmic mobilization and proliferation of stereotype.

he has ESP dude, he's a fucking cheater

We also note the utilization of exploits in systems, violation of moral coda, obstruction of play, obstruction of logistics (negating digital-affective-profiled economies), refutation of mobilization and blocking of any movement towards fulfilment. Griefing as the jamming of semiotic and affective smoothness (putting flies in the nebulous soup of feelsgoodman.jpg) vandalizing taste, injecting noise into a self-regulating system. Pain in the face of a homeostatic pleasure. Lulz. 
In a world where there is no alternative, perhaps the griefer reminds us to grieve for our possibilities, for those modes of experience excluded from the sprawling nodes of Facebook and our colonized relationality. Such a form of practice is understood to be a significant move from the hacker mentality of defending open source software and an 'Internet of freedom' to a position where such utopias are forgotten for the pleasure in subverting formatted inter-subjective relations, a pleasure that is rooted in the pain of others not their fulfilment. As the Unix Terrorist (a presumed hacker turned troll) describes his own position: 'what really drove me harder and further was the exciting possibility of using computers to turn the life of a particular fellow human being into a living hell' - a self-admitted form of medication for anomie. Epic lulz are what is at stake here, not the 'recycled academic masturbation' of hacking for a version of social justice.

No utopia of use, not happy hacking as thinly veiled consumption.

No semionauts strutting the digital streets and its mal(l)ware.

We find antagonism without aim, struggle without overcoming, division without an eye on resolution, two persistently not becoming one. The aim of generalized and monetized moral well-being replaced with chaos or formless-ness. A formal contentless crime to the network of feeling. A refusal of measure, a refutation of counting.

Nothing is more fundamentally challenging to someone - perhaps a model of social identity known as a dividual operating as a programmed slave in a cybernetic network - than crying over a video game.

Monsters demonstrating logics.

To turn to a pre-Internet writer who knows about transgressions within play, Georges Bataille reminds us that nothing is more serious than a communication transformed 
into burning words on a page, that moment when the fantasmatic solidity of identity liquiesces into a flux between states. Perhaps a user profile or an accumulation of points transformed, tears to be drunk by a squad of goons.

take the house apart, take the pets apart

low hanging fruit gives me no joy

You cant really grief a dead world can you?

Naah just pick at its bones

Figure 2: LM/FS (2016e), still frame from perpetual pacification as poisoned water, Gif file.

Let us now come to the curious situation of virtual worlds:

Leave networked RL [Real Life].

Enter SL [Second Life].

Enter Camp Poop, one-time home of the Yung Cum Bois.

furries, neckbeard trannies, memers, mutant goons, blender nerds, ageplayer vampire families, femboys, shopaholics, fashionistas, the brazilians, hairy gay hulks, linden alts, stalkers, breedables, botox lip findommes, unfunny YouTubers, banbox collectors, undertales, cloacas, bling, woodburies, mesh butts, boob physics, latex bondage ponygirls, gfx crashers, copybutters, anticopybutters, anti-anti-copybutters, anti-griefers, sandbox-foxes, thirsty beta males, escorts, cucklords, creepy daddies, the army of bots, L\$ beggars, group 
spammers, knowitalls, virtual weed dealers, sonic pedos, weebs, permanoobs, cowboys, angry bikers, dick pics, redlining violets, the 1337 haxOrs, the obsessive script kiddies, spergs, the angsty anons, brown nosers, the namedroppers,

Residual spaces: swamps, stagnant water, millenial dead-ends bewailed by selfdiagnosed 1/users. These places are the desiring machines of an obsolete future, meeting point of human subjectivities and virtual space, deadlands of once hopeful testbeds for new forms of community. In game we live in simulated space on borrowed time, singing as we build sunny islands on the surface of the heaving machine network. Remember the early Internet, it's anarcho-libertarian moment before the backslide of virtual enslavement, pixel-property developers, simulations of sociality. Here, left behind, washed up, loitering in the land that time forgot, a broken experiment of mnemo-technical traces.

Here we are confounded by anthropomorphisms, confused and ruptured groupings, newspeak. It is this ground we choose for our idling spot. A pathologized space where salty edgelords hang out in a parking lot.

A timeless zone, for each return the same game plays out.

Employment here is in collapse. We work nights on the meat counter at virtual Walmart. Paid in lulz and emoticons. There are bots on the tills. How shall we organize? Our sleep is destroyed.

Scripts are read and re-worked, parts acted out and upon. Words, worlds, offence and offensives, commons and division: all these played out in a dead-end game world, a simulated world oblique to the sprawled junkspace of selfies and networked profiles. 
Why did we venture into this tarpit? To see whether photogrammetric models were being deployed in world. We found few: one content creator producing kitsch artefacts and cultural heritage models compiled from crowd-sourced photographs and sold for profit inworld. We stayed anyway, to learn about low-poly modelling, gameready assets in a broad vernacular community of content creators. Who does the best builds? In our humble opinion, The Goons.

For the record we have been hanging with the YCBs. Useless pieces of shit, their geneaology may be traced back through The Wrong Hands, to W-Hat. Goons from the Something Awful forum, ancient rivals of the Woodbury University Patriotic Nigras (PNs), Digital Worlds, 4chan/VGs, sometime dastardly associates of the permabanned griffer-queen Skills Hak. The YCBs and W-Hats before them built collectively and thematically, modelling content, scripting actions and roleplay. Their symbolic milieux; Baku, W-HAT, RUDE, CVNT, POOP were 3D collages, a changing scenography of original content and found objects, generational elaborations, transindividual significations, collectivities and antagonisms.

the floor would vanish

and they would fall into a room

with spawners and bears that shot lasers

and chippys and all sorts of stupid shit

and people would be like ahhh

and they would freak out

and then leave 
We meet each other as avatars. We are invested, literally, in the production of identities, piloted images. We live in hollow objects, exoskeletal shields: an Aegis, that which we hide behind. The occupation of a model is an enarmoured position, first call in defending our RL identity against the ignominy of doxing, the posting of our personal information online, the fear of exposure.

\section{I sexually identify as an Attack Helicopter}

The exteriority of the world used to define the body. What do we come up against now? The haptics of inworld bumps and pushes. Is damage on? Virtual worlds exteriorize mental contents, play out a cultural unconscious, accumulate and combine into Hades. Digital objects here are revenant, zombie, inhabited, occupied.

What's in the shell? Yokai? Kami? Is there anybody there?

The avatar may be occupied, may be idle. It's a sleeper, its presence logs chat.

The avatar is a lumpen dead profile, but the body, the camera and the voice may separate. We can disentangle our senses from the body. We may listen from the camera position, some sort of synaesthesia. Voice hacks allow those so disposed to ventriloquise an object, or to speak from one avatar while their own, innocuously, sits idle. Seemingly unoccupied but present, cycling through automated gestures, life-like animations. Away from keyboard (AFK) we forget ourselves online.

An avatar is an investment. A player may spend months working on their ava, buying a body, skin, clothes, gestures and props, building presence, structuring feeling. We may each figure a multitude. My main, my alts, my throwaway accounts. What seems a multiplicity of characters may be the alts of one player, or one avatar may be inhabited by various people with a shared log in, a lesson we learnt from 
Julian Dibbell's 1993 essay 'A rape in cyberspace'. Identities kaleidoscope, fracture and cohere; roles are played out, souls are ripped out. We are banned, we return freshfaced, re-gendered.

\section{I got through 5 accounts already this month}

I love when they die

I love when they vanish

and people forget about them

so I can be someone else

The third person in this space is always referred to as 'them', not only are 'they' plural but we see here a clear refusal to assign gender with a pronoun. In this cumming community we are reminded that the antimony of the individual and the universal has its origin in language. The avatar disguises the nature of the game. The shell is just one aspect of the organism's morphology; it is the aspect most available to study, the dried material secretion of the gamer. We took up conchology.

Figure 3: Still from LM/FS (2016d), how to accommodate grief in your life, digital video, sound, 5:10.

We made virtual photogrammetric models of the idle avatars of the YCBs, congealing in each mesh their attached attributes and parts. We uploaded them and populated the world with husks and shells, mis-shapen doppelgangers. We learnt to animate them with scripts, twitching and deforming. We invented a form of virtual photogrammetry. What we did here is to harden and form the shapes of our 
imagination, the surfaces we uploaded and collected and compiled into an avatar, a mood board, a space, a sim. The images overlap and stick together like we've spilled milk on them. Photogrammetry necessitates that we shoot profligately, not framing an image but seeking to cover everything, over and over and over. Imbricated like the scales of a fish.

$i$ still dunno how to describe what you are doing but its like taking these moments, memories, things out of their times and putting them together into one time you are taking our lives and mashing them together like they're made of chewing gum that's a whole new level of trolling fucktards

Figure 4: LM/FS, Cactus Grrl and meat tent, photogrammetry models assembled inworld, Digital Files 2016.

The models were often resistant to compile, producing monstrous extrusions, amputations and composite forms. A mesh file acquired through photogrammetry will not be a well-formed object without substantial work. Despite the logic of simulation through calculation, things may not compile as they should. Algorithms are buggy, automatisms glitch. It will need artisanal assembly, retopology and cleaning to produce an efficient model. Low polycount is a matter of honour in online communities where render time, draw distance and level of detail are crucial to user experience. Low polycount is a kind of downsizing, or working to minimum specifications, a cultural form of austerity. It is achieved by decimation, a technique 
of cruelty, the enforcement of social responsibility through terror. The reverse process can be weaponized; a heavy mesh will crash you:

it's a big red mesh alpha with tons of vertices and tessellation and it's all glowing and bright

like seeing the face of god

I have a picture of a person who could see it without crashing

it was just messing up and fracturing all the images

it broke their gpu anyways

A meshing or gathering together of images.

An image-agora, the screen replacing the town square, the projective technical image finding us in a private abode to feed us public knowledge. Erosions of the private, redundancy of the public.

The gestell can be useful to thinking about an apparatus: not a machine or a tool, but a total system within which we inhabit. A representational space as field; this dump as our agora. The world as image dump.

Image dump as a gathering, as apparatus, as social field shot through with pictures.

As images we wander.

Modes of imaging and modes of interaction; from the split cocoon of the photographic oozes the somatic body.

We spawn. We assemble.

Image boards, such as 4chan or reddit, are organized by a logic of the image dump, arranged around an ecology of refuse and re-use. Anonymous users forming 
visual bonds through their shared interests and de-authorized actions. Images are dumped into the flow outside of their initial context, reframed as they come together with text and networked protocols. Image dumps of gore pictures, spiderman macros, cute cats, hacked Facebook nudes, archives of booty from The Fappening conquests.

An image dump as a vomiting up and out of image as relational quantity and moral inversion, a logic of fast-paced scrolling, conversational rebuttals and hoarding, not contemplation or divination. Images as coin in net-banter barter, a binding of an alternative social logic, the logic that privileges lulz accumulation over profile links and likes. Photographs as part of a griefing strategy, not photographs as mourning or anomic promotion. The shadow of the selfie-ridden profile.

Images as exclusion zone: the utilization of images that shock in order to keep the cancer of new users away.

An image community that police against an influx of newcomers with images that exceed moral computation. A world without valour.

Trolls against white knights.

Georg Simmel talks of the difference between bridges and doors in the world. While the bridge may connect parts that would otherwise be unconnected, the door is that which may be opened, providing access but also exclusion. Images as doors, then. Opening and shutting. Granting access or denying inclusion to a troll dwelling. Images are scavenged and reworked: remediations that exceed contexts, that render directions null. Attenuated de-identified image flow as semio-linguistic bond of the anons.

\section{Sauce?}


We see the logic of this image dump furthered in the YCB and Goon-culture of Second Life. The images are dumped, bonds are created, worlds are spatialized. Images are imported, activated, spammed. Image veils code, a life raft upon the seething Matmos. Russian dolls and wrappers. A logic of photographic calumny as images are weaponized and transformed from a flow in a chain to a movement against taste or decrees of acceptability. This logic is one that defines image-board culture also, a flow of images that bond but also that reject; the normalcy of the average luser will self-eject when spending too long in the swamp. A similar logic governs the builds of the Goons. A spitting out of tropes and redirecting stereotypes into traumatic instances: the dreamwork of the monstrous id, the super-egoic laughter at the self's failure to produce the goods.

We're gonna suck the memes out of you

Vernacular use of 3D modelling in online multiplayer environments disrupts conventions of artistic and social production, governance and copyright. We can trace the Pathos formula of a model, wrapped in a Universally Unique Identifier (UUID), generating a new 128-bit number with each saved iteration. We make a model of an avatar, drop a copy in world, someone adds a red nose, another cuckold horns, we model it again now, copies are taken, rezzed in another sim, dressed with hats, scaled huge, posed with lewdly. Images get posted on 4Chan. Fame, then the thread dies. Original poster (OP) is a fag. What we have witnessed is a small example of the movement of networked data, expressed in hits and surges. What it does is not so much transport image or object, but connect nodes.

Game world environments play out the achievement of goals and rewards 
through digital labour in ways that have been said to compensate those disenfranchised and unemployed IRL. In $S L$ we drive a customized Maserati into the swimming pool. Our pneumatic boobs have their own physics. We throw shapes, the extravagant outline of aspiration. We exercise our entrepreneurial freedoms in the marketplace. We wear bling, play the slots, shop for exclusive designer gear and live in a Le Corbusier house gated behind ban lines, protected by a security orb, on a private island with our family, breedable pets and a choice of functioning cocks. Our perfect lives. But this happy 'good life', our own private idyll, is disrupted one day by truculent and provocative actions. Our private erotic roleplay (ERP) is interrupted by hyena laughter. Our happiness reverts. Objects start moving on their own. The sky is filled with offensive images. Chat is spammed:

[shouts] NEBULA SAYS: YOUR DEAD, YOUR FRIENDS ARE DEAD, YOUR MOTHERS A FUCKING WHORE, YOUR FUCKING PETS ARE BEING SKINNED ALIVE, YOU JERK OFF TO AVATAR PORN, GAME FUCKING OVER LIVE WITH IT!

NEBULA SAYS: YOUR DEAD, YOUR FRIENDS ARE DEAD, YOUR MOTHERS A FUCKING WHORE, YOUR FUCKING PETS ARE BEING SKINNED ALIVE, YOU JERK OFF TO AVATAR PORN, GAME FUCKING OVER LIVE WITH IT!

Swamped by peurile automatisms an agonistic public space erupts. Bored scripters learn how to break things and make toys. Is that a brony avatar or a trojan horse? Paradise island dies in a flood of grey goo. Grey Goo is a scripted object attack; once spawned an object will self-replicate, continually spurting out copies of 
itself, lagging the sim, slowing your framerate, consuming land resources.

key OldID;
key NewID;
string Name;

default

\{

touch_start(integer $\mathrm{t})$

\{

11SetStatus(STATUS_PHYSICS, TRUE);

11SetTimerEvent(5);

Name $=11$ GetInventoryName $(6,0)$;

\}

on_rez(integer s)

\{

$\operatorname{if}(\mathrm{s}==1)$

\{

11SetStatus(STATUS_PHYSICS, TRUE);

11SetTimerEvent(5);

Name $=11$ GetInventoryName $(6,0)$;

\}

\} 


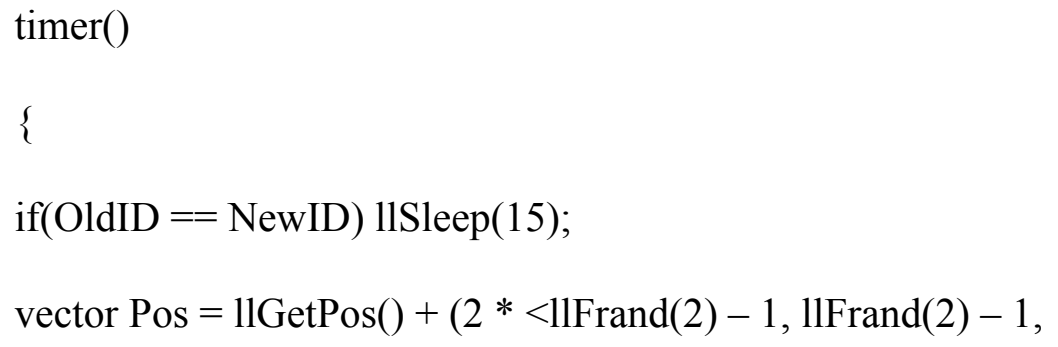

Execute the script. We encounter something like image metastasis, mediatic spectacles choreographed for the Lulz to purposefully exhaust and enrage. Traumatic and violent photographic images are mobilized and performed alongside old memes and cartoons. Particle scripts, an old toy, may be used to conjure dense clouds of images that proliferate to obscure the surroundings of the user, spamming them, making it difficult to navigate the environment, strangling the stream, causing grief. It is a collage medium that disrupts the convivial: automated image as blockade to dividualized avatar. Neither a window nor a map, it is a cloud, a wall, a barricade, a brickbat. 
A blinding swarming spawning.

Images not to show but to slow and stall.

Image dump as image spam. In post-renaissance accounts the image becomes a window onto the world, a thing that is 'seen through'. This method is supplanted by assaults on perspective and legibility that define much twentieth-century practice. Here, in $S L$, the practice of collage as that which disrupts, or as that which connects what is otherwise unconnected continues. The image takes on a haptic quality refusing distance or control, an impression of photographic technics. Images refusing frames, refusing pictures, image dump as refuse and refusal: midden as heat producer, steaming excitation. Benjamin talks of an image with an impact - of the hybrid photomontage with a ballistic quality, a projectile force that happens to us. We liken this recent movement in the assault of images in virtual worlds - the self replicating object, the particle script - as both technique of spam and of photomontage.

To think of these scripted image-objects as photomontage we need only turn to some of Benjamin's definitions: montage as the alienation effect, as disruptions of actions, as the insertion of something discontinuous into a continuity. A distracting projection not a site for contemplation. Hito Steyerl notes that spam, as a ubiquitous form of digital debris and the excrescent matter of digital life par excellence, has a multi-layered character. It can serve to blockade communication, a form of trashing, obstruction and displacement. As part of a scammer's ruse it can attempt to waste time or resources, grab attention and dig out liminal sparks of value that might lie dormant in the social field. Adopted by pioneering spammers on earlier online collaborative games the term originates from a comedy sketch, where the word 'spam' refers to the food product of indistinguishable meat stuff, but also becomes an uncontrollable replicant thing: proliferating until all meaning is lost, until historical 
and cognitive coordinates are indecipherable. Steyerl sees this term as a possible metaphor for our contemporary existence where attention is endlessly exploited, where meaning and bodies are ground into pulp, where our psyches are fed postcarnal fantasy mash-ups, but also as a site of resistance.

Spam as obstacle, as obstruction to communicative vectors.

Spam as a public matter, an assembly drawn from an intermixture of sources, impure, common.

A blockade to logistics and also an erasure of class distinctions, Steyerl urges us to assume spam's potentially radical character.

An ambivalent form of montage, spam potentially works on attention in the way that Benjamin asks us to think of the radical character of distraction: a distracted viewer might veer off into the unknown. Spam as an obstacle to communicative work. Exploiting links between community and attention spam points to the possible deactivation of productivity as well as the endless whirr of the meat grinder. Jean-Luc Nancy gives us the model of the community as one in which communication is the very suspension, or unworking, of work. Spam as the inoperative. A reframing of willed activity and duty.

The opposite of austerity politics.

Kill by super-abundance.

Find the exploits, 'opening the floodgates' so to speak, to overburden the system and eventually lead to its failure. For instance, a flood of images on cubes consisting of many duplicates raised at once, which all begin to process scripts, placing massive demand on the asset server. It all basically functions in the same way a conventional Distributed Denial of Service (DDOS) might work; overload the system and force it to slow down to a halt. As we understand, little bugs still allow 
that to work; for example, java engines that have not properly coded limits to infinite calculations. Images or textures are utilized in an asset crasher to disrupt the medium; the communicational vector between the server and the local computer. A texture map is an image applied or mapped onto the surface of a shape or mesh, usually stored in a common file format, JPEG2000, .png or .jpg. Cloned objects, a twisted prim for instance, may be filled with gigabytes of texture memory and a simple script for cycling through image files superfast. Drag click to make them larger, the sim will stutter. Link them together and it crashes the server, or freezes frames in the sim. Zero framerate, No upstream, no downstream. Choked.

\author{
Use a valentines day card to crash a sim, \\ an old joke \\ A really stupid thing with a really big script in it. \\ You opened it, \\ you clicked the card \\ and the sim would crash.
}

Griffer toolz.

The griefer's gift. Distributing love's epistolary codes and behaviours through a digital social system, a world of compulsory happiness. A sucker's time bomb. An ambivalent token.

Eventually, one way or another, all lover's tokens and silhouetted medallions whether by intent, ritual deposition or accident, end up in the trash. This stinking heap is a ground of radical indeterminacy. Our cultural safety markers slide seamlessly into the cess-pool. We lose our context. The archaeology here is one of unknowable 
intentions, unproveable knowledge, dreamworlds and intuition. Positions are inflammatory, flaunted, contradicted, expressions of revanchist resentment. The griefer plays with anathema, prods at tolerance with a rainbow bayonet. Nothing is what it seems. What it seems is in our heads. We have to make up our own minds. That is something.

The image dump is stratified redundancy, a site of scavenging misanthropy, of unintendable cognitions and contingent fabulations. One dip in the poisoned water reveals the mnemo-artefacts we call stereotypes - that is, automatic habits and volitions - profaned into traumatypes; intensified, glistening, things to be repressed or expressed in symptoms and fantasies, executed inworld, to grief.

Poison and cure.

'Sup?

Figure 5: Still from LM/FS, (2016a), would you die for me, digital video, sound, 7:07.

don't go changing, he said

and set me on fire with a flame thrower

later, $i$ met him in the parking lot

you always have my unspoken passion, $i$ said

although I might not seem to care

then he gave me a paw

my own paw

$i$ had been copybotted

one by one they gathered around 
they built a pleasure dome

they turned up the sounds

they sprouted hair and paws

and obscene tail stumps

one by one they began to transform

into me

distorted wretched

dancing in a frenzy

after that $i$ could walk on two legs

We joined the YCBs around the campfire roasting marshmallows, at Christmas 2015.

We build around a hearth. Drawing in. Casting shadows, tracing affect. Heaping mounds of refuse into the dark around us. Living in a midden of unindexed files and hot drives.

We saw the campsite razed, the land get developed into Walmart where we worked nights on the meat counter and were eventually promoted to security. We turned bad and went on a few raids. Got parcel-banned and permafrozen.

All in this together.

Things were happening fast. IRL expropriations were taking place on our doorstep. We recorded those buildings in $3 \mathrm{D}$ and uploaded the models. We started to talk to the YCBs IRL. The prophets were calling the end times: purge, ban. We began to record: inworld snapshots, screen grabs, transcribed chat logs, voice recordings. By March the ship was sinking, rats on the deck.

Poop went down the chute forever. 
Out of the debris we constructed poems. We asked our friends to read them. We asked them for their scripts and made our own images fly and bounce. We are making videos.

So this is something, out of a churned sea of associations.

A ventriloquy of voices, a concatenation.

We call it Conflictual Circulation, and we end with your reading it now.

Aloud.

I.

User orientation

Content generation.

A user's busy intelligence.

I am not thinking about you.

Adopt. Adoption, adaption, adaptation.

Aptitude. Adaptible.

A battleground of competence.

A right of engagement.

Going in Hot!

Going Loud.

Singing Ludd's song. 
Lusers / Haxzorz,

133t speak drone buddies

Sage your emotional design

and your public experience center.

Prosthetic Narcissus.

Disturbance and Puppets.

The wisdom of the crowd

The brutality of the mob

Swarm intelligence

Hivemind juvenilia

A human universe of symbolic negativity.

The People subtracted from the Multitude

Condensation of data-pools, re-aggregated potenza.

Bubbles and riots

Bundled contradictions

Freemarket communism as Facebook revolution fetish.

II. 
Knots through differential fields.

Practical optimism of enduring struggle.

Affective contusions.

Self-posited

To struggle and reconcile.

The illusion of taking sides

Engaged positions emerging through mutual destruction

Without justice.

No honour

No virtue

Or,

Negativity as Master.

Finitude as horizon line.

Self-contradiction as obstacle.

Enemies as props to mask non-absolute inconsistency

Ladies and Gentlemen; We got 'em.

Or him, or you.

Identity predicated by an enemy who veils the failure of 'I'

Immanent disintegration displaced and projected.

I am our hatred of others.

Defeats that bring us to the truth. 
Level playing

Through open source fields

Actionable script instruction

Sonic malware downloadable

Re-gendering congealment

Slinging weapons and profiles

Payment confirmed.

Redefining beta.

III.

Interactions as sociation

If you want peace prepare for war

Conflict as resolution of contrasting determinations

Negation termination indifference

Enjoying your ban

Nuclear impending

Continual threat impeachment

Rejecting light

Defending swamps

Stuck in the mud

Filthy festering pit

Wet edge sucking sighing.

To know so little of the ignorance that starves you 
Rolling with the fanboys enarmoured with thorns

Meat for the grinder

An arrogance of the kingly

Self-harming shadows weighed down, buckling, baulking

Turned teeth upon themselves

Dabbled in the minestrone

A raged sousing with swill.

How to make a viable build.

Vidya ethics

Law of averages is a strong force

Major league gaming bass cannon

Ganking spanking suffering

Alpha topping

Git gud memeology

Weeaboo waifu junkyard

the more you fuck over people

... and the more you get fucked over

Karma fluid fickle

Mumble cum nozzle 
IV.

Psychic Counter-Revolution.

Absolute equality or Absolute administration?

Gears, cogs, regulated components of a system

Ensured cohesion and equilibrium of a whole.

Slaves and barbarians

The nature of ruling.

Mysteries and glories of governance.

Cybernetic enslavement and the foreclosure of the common

Barbarism and the failure to produce a world.

Infinite circularity or thickness of being?

Subaltern glitch and twitch.

Physicality detached facing us down.

Friends and allies.

Terror threats.

Militainment operations.

Johnny One-Shot as part of a complete continuum.

... from the pettiest crime to insurgency proper,

Incivility, threat;

Civil-military integrated response. 
Its happening!

or Party Van Time

Low Intensity Operations.

Perpetual pacification as poisoned water.

Keeping the peace is a full time war against the uncivil

A university of social justice

Crashed tankers

Spilled milk to drown the baby

A preventative logic against social war machines

A discourse on violence;

CIVIL WAR and the limits of community.

International peacekeeping.

Culture and refinement.

The matter of holding out a lollipop.

Abominable dogbiscuit rhetoric.

Horrible agglomerate compost.

Puffed words.

Puff-Puff.

Unlink.

Unlike.

This is not the right place, but nobody wanted us. 
Idiocy as ignorance of community.

Those that know not the town square but only the navel.

Paradoxes of cellspace

Doxxing matter of bordered civility.

Privacy and privation.

Backdoor exploits.

Explicit facial.

Vampiric relations.

I remember you.

Bunched vectoral parasites.

Exploits between community and attention.

V.

Language as the placeholder of negativity.

Ethics as the home of the voice.

Words as the death of thought.

To come journeying through black air, good. 


\section{Acknowledgements}

We thank all YCBs whoever you are, whatever you are, wherever you are. We also thank Catherine Grant for tough reading and good humour.

\section{References}

Agamben, G. (1993), The Coming Community (trans. Michael Hardt), Minneapolis, London: University of Minnesota Press.

Bakioglu, B. (2009), 'Spectacular interventions in Second Life: Goon culture, griefing, and disruption in virtual spaces', Journal of Virtual Worlds Research, 1:3, pp. 3-21.

Bataille, G. (2014), Inner Experience (trans. S. Kendall), Albany: SUNY Press.

Benjamin, W. (1969), 'The work of art in the age of mechanical reproduction', in H. Arendt (ed.), Illuminations (trans. H. Zohn), New York: Schoken Books, pp. 211-244. (1998), 'The author as producer', in Understanding Brecht (trans. A. Bostock), London: Verso, pp. 85-103.

Beradi, F. (2015), And: Phenomenology of the End, Los Angeles: Semiotext(e). 
Brunton, F. (2013), Spam: A Shadow History of the Internet, Cambridge, MA: MIT.

Coleman, G. (2012), 'Phreaks, hackers and trolls: The politics of transgression and spectacle', in M. Mandiberg (ed.), The Social Media Reader, New York: New York University Press, pp. 99-119.

Darling, J. (2012), 'Arcades, mall rats and Tumblr thugs', New Inquiry, 23 February, http://thenewinquiry.com/essays/arcades-mallrats-tumblr-thugs/. Accessed 28 July 2016.

Dibbell, J. (1993), ‘A rape in cyberspace', http://www.villagevoice.com/news/a-rapein-cyberspace-6401665. Accessed 27 July 2016.

Fuller, G., McCrea, C. and Wilson, J. (2013), 'Troll theory?', Fibreculture Journal, issue 22, http://twentytwo.fibreculturejournal.org. Accessed 28 July 2016.

Flusser, V. (1990), 'Television image and political space in the light of the Romanian Revolution', https://www.youtube.com/watch?v=QFTaY2u4NvI\&feature=channel_video_title. Accessed 28 July 2016.

Hak, S. (2016), 'I know everything happens for a reason', http://skills.tumblr.com/; https://tmblr.co/ZUmpay23zxGmh. Accessed 27 July 2016.

Joselit, D. (2011), 'What to Do with Pictures', October, No. 138, pp. 81-94. 
Kelsey, J. (2012), 'Next-Level Spleen', Artforum, September, pp. 412-15.

Linden Lab (2003), 'Second Life [computer programme]', http://secondlife.com/. Accessed 28 July 2016.

LM/FS (2016a), would you die for me, digital video, sound, 7:07, https://www.youtube.com/watch?v=5vqCtjqbBcY. Accessed 27 July 2016.

(2016b), singing in the rain, digital video, sound, 3:23,

https://www.youtube.com/watch?v=WSGfcuiQd5Q. Accessed 27 July 2016.

(2016c), luchador grieves, digital video, sound, 4:27,

https://www.youtube.com/watch?v=Feh7j7fjHGA. Accessed 27 July 2016.

(2016d), how to accommodate grief in your life, digital video, sound, 5:10, https://www.youtube.com/watch?v=FQ6r5rtRgQQ. Accessed 27 July 2016.

(2016e), perpetual pacification as poisoned water, GIF file,

http://skinnersroomfiveyears.blogspot.co.uk/2016/06/conflictual-circulation.html. Accessed 28 July 2016.

Marazzi, C. (2011), Capital and Affects: The Politics of the Language Economy, Los Angeles: Semiotext(e). 
Minkin, L. and Dawson, I. (2014), 'Object lessons: Copying and reconstruction as a teaching strategy', Art, Design \& Communication in Higher Education, 13:1, pp. 1929.

Nancy, J.-L. (1991), 'The inoperative community', in P. Connor et al. (eds), The Inoperative Community (trans. P. Connor et al.), Minneapolis: University of Minnesota Press, pp. 1-42.

Phillips, W. (2011), 'LOLing at tragedy: Facebook trolls, memorial pages and resistance to grief online', First Monday, 16:12, http://firstmonday.org/article/view/3168/3115. Accessed 28 July 2016.

Simmel, G. (1994), 'Bridge and door', Theory, Culture \& Society, 11:1, pp. 5-10.

Steyerl, H. (2011), 'Digital debris: Spam and scam', October, No. 138, pp. 70-80. (2013), 'Too much world: Is the Internet dead?', e-flux, Journal \# 49, http://www.e-flux.com/journal/49/60004/too-much-world-is-the-internet-dead/. Accessed 28 July 2016.

Stiegler, B. (2010), For A New Critique of Political Economy (trans. D. Ross), Cambridge: Polity. 
(2014), 'Organology of dreams and archicinema', The Nordic Journal of

Aesthetics, No. 47, pp. 7-37.

(2016), 'Hades as an accumulation of tertiary retentions', unpublished talk,

Warburg House, Hamburg, Germany, June.

Stoichita, V. I. (1997), A Short History of the Shadow, London: Reaktion Books.

Terrorist, U. (2008), 'Phrack profile on the UNIX terrorist',

http://phrack.org/issues/65/2.html. Accessed 28 July 2016.

VNS Matrix (1991), 'A Cyberfeminist Manifesto for the $21^{\text {st }}$ Century', located at http://adanewmedia.org/files/2014/07/VNS.png, Accessed 8.08.16

\section{Contributor details}

Louisa Minkin \& Francis Summers are based in London, UK. We have made work together since 2012. The by-products of this labour have taken the form of websites, banners, performances and videos.

Contact:

E-mail:1.minkin@csm.arts.ac.uk

Central Saint Martins

Granary Building

1 Granary Square 
King's Cross

London N1C 4AA

UK

E-mail: fsummers@uca.ac.uk

UCA Rochester

Fort Pitt

Rochester

Kent ME1 1DZ

UK 